their own, they remain the most direct way to test a hypothesis about the function of a region of the human brain. Therefore, it is noteworthy that the incidence of aphasia following damage to the right hemisphere appears to be no higher in women than in men ${ }^{3,4}$, contrary to what would be expected if women were more dependent on the right hemisphere for language.

Nonetheless, the findings of Shaywitz et al. strongly suggest that future studies on the effects of right hemisphere damage may reveal more subtle sex differences in language function than those that can be detected by clinical tests for aphasia. They also indicate that a good starting point would be patients with lesions of the inferior frontal gyrus.

Michael Rugg is in the Wellcome Brain Research Group, School of Psychology, University of St Andrews, Fife, Scotland KY16 9JU, UK.

\title{
Flight into pre-history
}

\section{Paul G. Bahn}

EIGHT years ago, Nature carried a paper ${ }^{1}$ and associated News and Views article ${ }^{2}$ describing the discovery of an Upper Palaeolithic 'boomerang', made of mammoth tusk, from Poland. But the object was far too precious to be used for tests to see how well and how far it flew, so such tests have had to await the construction of realistic replicas. The ballistics experiments have now been carried out with plastic copies ${ }^{3}$. They show that this was a formidable weapon although, as was thought from its shape which is similar to that of some wooden specimens from Queensland, Australia, it was not a returning boomerang but a straight-flying throwing implement for use in hunting.

The boomerang, the only ivory specimen known from prehistory, is made from the end of a young mammoth's tusk; its span is $71 \mathrm{~cm}$, and greatest width and thickness $6 \mathrm{~cm}$ and $1.5 \mathrm{~cm}$ respectively. It was originally thought to be about 23,000 years old, but accelerator radiocarbon dating has now assigned it to around 20,300 . An exact replica was made in plexiglass, from which a copy was taken in plastic of the same specific gravity as mammoth ivory (1.8 to 1.9). The facsimile weighed about $800 \mathrm{~g}$.

The first tester, an expert in the field of throwing implements, had difficulty in throwing the boomerang. Not only is $800 \mathrm{~g}$ quite heavy for objects of this type, but the span and outline are unusual. The two ends are of different widths - the wider arm is clearly the gripping end, for the thinner arm, because of its greater curvature and less favourable position in the hand, could injure the thrower as its point slides through the hand. The broader point also has transverse engraved lines on its underside which afford a better grip.

The boomerang can be thrown with either the right or left hand without any loss of flight qualities: in a right-handed throw, there is a typical dive and rightward turn at the end of the flight path, caused by a strong decrease in rotation speed but not in forward propulsion. The tester threw the facsimile at an angle of $80-90^{\circ}$, almost horizontally; it slowly reacted to minor turbulence and brief shifts in wind speed, but its flight path proved extremely stable (whereas that of a wooden specimen, weighing only $200 \mathrm{~g}$ and with a span of $50 \mathrm{~cm}$, was clearly influenced by wind conditions). Throwing the object horizontally prevents excessive lift. This may well have been intentional on the part of the carver, because a hunting weapon with excessive lift hinders aiming, and game can spot it too soon

With a following wind, the average flight path was $25-30 \mathrm{~m}$; with the wind to the left or right, the average was $30-35 \mathrm{~m}$; but against the wind the average path was $35-40 \mathrm{~m}$. In other words, wind propulsion from behind had less effect on the distance thrown than the aerodynamic lift from a facing wind. The same results were obtained in summer and winter and in a variety of weather conditions.

Further tests were carried out by two sport-boomerang enthusiasts. In a wind strength of 2 on the Beaufort scale (a light breeze), various attempts confirmed that only a horizontal throw was practicable and sensible. The best throw achieved was $66 \mathrm{~m}$, with a gentle facing wind (3 on the Beaufort scale).

For comparison, they also threw a bent wooden cudgel with a round cross-section, loaded with lead to weigh $800 \mathrm{~g}$. It was easier to hold than the boomerang, but its blunt cross-section acted as a brake - it travelled only $27 \mathrm{~m}$, at $18.5 \mathrm{~m} \mathrm{~s}^{-1}$, whereas the boomerang went up to $66 \mathrm{~m}$ at $21.4 \mathrm{~m}$ $\mathrm{s}^{-1}$. Comparisons from modern athletics are the world records for men's javelin $(800 \mathrm{~g})$ and discus $(2 \mathrm{~kg})$, which are around $95 \mathrm{~m}$ and $75 \mathrm{~m}$ respectively. For obvious reasons the testers could not try their skills on live targets (which, originally, were probably small game).

Subtle details in carving of the ivory, all apparently designed to improve the boomerang's stability and ballistic qualities, indicate that its maker knew precisely what to do. Its ingenious form points to a long tradition of making weapons of this kind; the carver was clearly drawing on long-accumulated knowledge in the working of this difficult material.

Paul G. Bahn, a freelance writer on archaeology, is at 428 Anlaby Road, Hull HU3 6QP, UK.

\section{Valde-Nowak, P., Nadachowski, A. \& Wolsan. M. Nature 329, 436-438 (1987) \\ 2. Bahn, P. G. Nature 329, $338(1987)$ \\ 3. Evers, D. \& Valde-Nowak, P. Archäologisches} Korrespondenzblatt 24, 137-144 (1994).
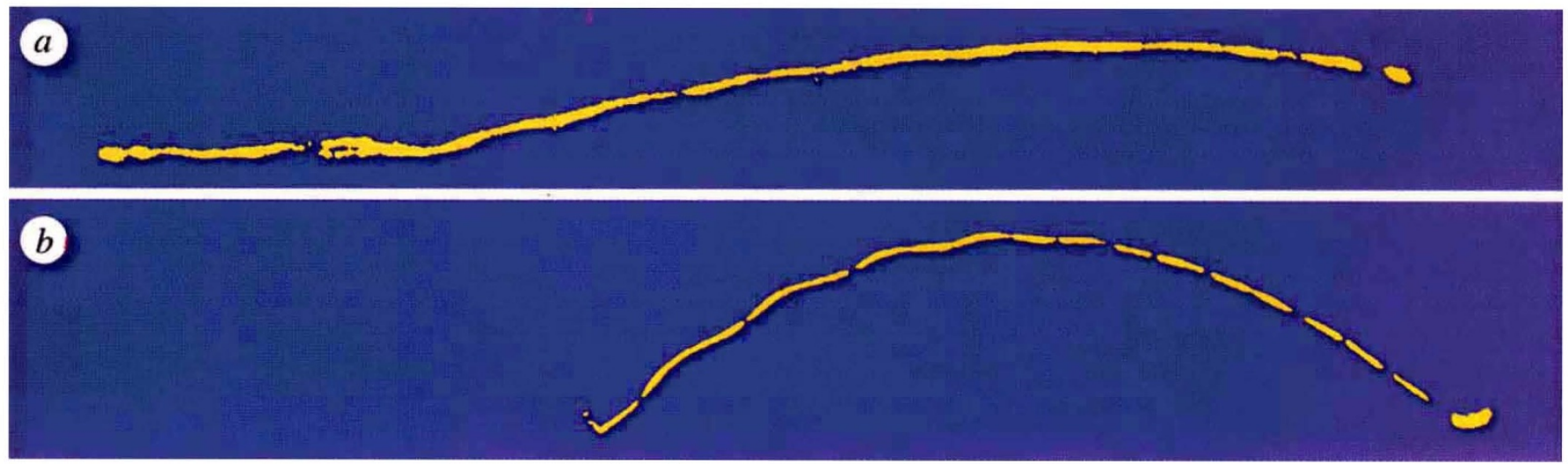

The flight path, running from right to left, of the replica 'boomerang', coated with luminous material and thrown at night (a) against that of the similarly prepared wooden cudgel $(b)$. The top trace is clearly the flatter and longer. (From Fig. 7 of ref. 3.) 